\title{
Research on the Employment Competitiveness of the Local Colleges and Universities of Economics and Management Majors Students in the Background of Internet Plus
}

\author{
Qiqi Wei*, Xiuying Qin
}

Guangxi University of Science and Technology, Liuzhou, Guangxi Zhuang Autonomous Region, China

${ }^{*}$ Corresponding author. Email: 85638562@qq.com

\begin{abstract}
The New formats based on Internet has become a new driving force for economic growth. the paper analyzes the contradiction between the cultivation of high-quality talents and social needs in the era of "Internet plus", demonstrates from the aspects of educational resources, employment concepts, training orientation and occupation career planning, and finds out the ways to improve the employment competitiveness of the local colleges and universities of economics and management majors students. Professional evaluation and information technology innovation and entrepreneurship education are the key points of innovative talents training mode and applied talents training.
\end{abstract}

Keywords: Internet plus, Employment, Mode, Competitiveness.

\section{“互联网+”背景下地方院校经管专业学生就业竞争力研 究 韦齐齐*，覃秀樱}

\section{广西科技大学, 广西柳州, 中国}

*通讯作者. 邮箱: 85638562@qq.com

\section{中文摘要}

基于互联网的新业态成为新的经济增长动力, 本文通过分析“互联网+”时代高质量人才培养与社会需求的矛盾, 从教育资源、就业观念、培养定位、职业生涯规划等几个当面进行论证，找到了提高地方院校经管专业大学生 提高就业竞争力的路径, 其中利用大数据开展职业测评、信息技术好创新创业教育是创新人才培养模式、培养 应用型人才的重点。

关键词: 互联网+，就业，模式，竞争力

2015 年 7 月 1 日,《国务院关于积极推进“互联网+” 行动的指导意见》(国发〔2015)40 号), 被称为释 放“互联网+”战略设计信号的“十一项”, 提出互联网
要与经济社会各领域的深度融合发展, 以互联网为基 础的新业态成为新的经济增长动力, 互联网成为经济 增长、产业结构转型升级、提供公共服务的重要手段。 
五年来, 在这一政策的驱动下, 社会发生了重大变化。 坚持改革创新、依托互联网技术、以市场需求导向、 顺应世界“互联网+”迅猛发展态势, 成为构筑经济社 会发展新优势和新动能的最强音。在社会转型、产业 重构的阶段, 地方院校的经管大学生的专业课堂学习、 专业实习实践还没有来得及适应改变, 加上毕业生人 数众多、企业需求多变, 就业竞争力压力非常大。在 严峻的就业形势下，如何提升就业竞争力、缓解就业 压力, 解决大学生就业创业难的问题, 成为地方院校 关注的重点问题。

\section{1. “互联网 + ”的概念和内涵}

“互联网+”在上个世纪初首次被提出, 随着互联网 技术的快速发展和普遍应用, 各个行业发展格局受到 了很大影响, 而传统行业与互联网技术的融合, 促进 了很多新兴经济和产业的崛起, 有效带动了我国市场 经济的发展和创新。“互联网+”是把互联网的创新成 果与经济社会各领域深度融合, 推动技术进步、效率 提升和组织变革, 提升实体经济创新力和生产力, 形 成更广泛的以互联网为基础设施和创新要素的经济 社会发展新形态。(出自国务院关于积极推进“互联网 +”行动的指导意见） “互联网+”作为一种新兴的经济 模式, 也是一种思维, 影响着人们日常的学习、工作 和生活, 甚至改变了长期以来的习惯和生活方式。在 某种意义上, “互联网+”是一种宏观的经济发展格局, 有效顺应了时代、技术以及现代化经济的发展趋势, 现如今互联网的广泛应用和推广极大地改变了市场 经济的大环境。

\section{2. “互联网+”时代经管大学生就业的特点}

\section{1. 大数据时代为大学生就业提供了新思路}

大学生每天通过手机活跃在各大社交平台, 他们 活跃的场所、交易的记录、汶览的信息, 被各种看不 见的网进行数据采集、分析, 从而被大量的信息推送, 无法阻挡。教师队伍不完善的情况下, 大学生自身存 在的如自我认识不足, 对职业兴趣认识不足、就业目 标模糊等问题, 不能得到很好的指导和解决。加之大 学生就业期望值多元化、理想化, 就业结构性矛盾更 加凸显, 因此, 为了长远的生涯发展而深入探索自身 相关或感兴趣的专业方向, 通过系统、科学的“职业 测评”, 并生成相应的数据对比分析和结论, 是十分 有必要的, 用数据说话, 以期求职定位更加精准, 目 标更加明确。

\section{2. 线上线下招聘相结合为大学生就业提供 了多元化平台}

随着互联网技术与传统行业的深度融合, 经济社 会的快速发展, 网络环境形势越来越好, 双选会、招 聘面试等呈现多元化, 催生了就业平台的多元化。网 站、APP、微信公众号、小程序等都被开发成为就业 平台, 通过微信、H5、微博等信息发布约来越多, 钉
钉、腾讯、Welink 等数字媒体平台都已经成为网络招 聘的新方式。通过这些平台, 用人单位可以召开视频 宣讲会，与应聘大学生情况进行“一对一”或者“一对 多”视频面试, 甚至相应的考试也能通过平台进行。

\section{3. 互联网技术的进步为大学生就业提供了 多重保障}

互联网就是一把双刃剑, 网络环境复杂难测, 为 防止大学生求职陷入“陷阴”“虚假”“纷争”, 我国在宏 观层面已经对“云上招聘会”“空中双选会”提供了系 统、全面的政策保障，对参加线上招聘的企业明确了 相关的管理规范和政策机制，对各类平台的人才招聘 市场进行有效的监管，降低了“互联网+双选”下大学 生求职的风险。同时, 国家要求相应求职平台要公开 相关信息, 要求政府设立的招聘平台给予求职学生相 应的政策指导。

\section{3. 经管类大学生就业市场矛盾}

就业是民生问题，事关社会安定，稳定就业能减 少社会矛盾和不稳定因素。随着社会的进步和时代的 发展, 当代大学生的求职标准发生很大变化。原来的 毕业生求职主动、积极, 更容易满足, 由于观念的转 变和生活条件提高, 如今的毕业生不但增加了许多新 要求, 且更加强调自我实现以及兴趣、爱好。这给人 才市场增添了许多新的研究课题, 既有总量上的供需 矛盾，也有人才匹配的结构性矛盾。

从用人单位对某地方院校经管类毕业生的能力需 求倾向调查可知，百分之九十的用人单位对毕业生的 工作态度和责任感的要求排在第一位，排序靠前的依 次为沟通能力 $(85 \%)$ 、团队协作能力 $(85 \%)$ 、适应 能力 $(81 \%)$ 、创新能力 $(77 \%)$ 等。这些能力通过专 业学习和社会实践而获得, 在实际工作中既能满足社 会需求, 又能实现自身价值。具备一定的就业能力, 有助于经管大学生在激烈的人才市场竞争中认识自 我、找准定位, 并找到自己想要的岗位。对企业而言, 能较快适应实际工作要求, 尽快帮助企业实现企业竞 争力和价值，也意味着“人职匹配”高度契合。

在互联网时代，随着大数据的快速发展和产业经 济结构的转型升级, 经管类大学生就业受到很大的冲 击, 社会和企业对经管类人才能力的需求日益增高, 经管类大学生就业竞争严峻, 正确认识经管类大学生 就业竞争力影响因素, 是解决和提高经管类大学生就 业竞争力的首要任务。

\section{4. 影响地方院校大学生就业竞争力的原因分 析}

\section{1. 教育资源不平衡}

地方院校教育资源不均衡问题随处可见，有其较 为深层次的原因。同样是经管专业, 在工科见长或理 工科背景的高校, 与文科类为王牌的学校, 其投入是 
有很大区别的。高校的教育投入与产出总体而言还是 正比关系，获得拨款越多、投入越大的学校，学生能 享受的资源别其他高校要新、全, 学生掌握的知识和 技能也随之水涨船高。举个例子, 有些地方院校的实 验设备老旧而缺乏资金更换，目前学生用的实验平台 还是十多年前的，有的甚至二十多年前的，不但知识 更新跟不上社会的发展, 思想理念还停留在互联网早 起时代, 其操作技能和实训水平都更加令人堪忧。而 有些高校已经采用“云课堂”“翻转课堂”“慕课”等方式 进行弥补, 线上线上授课, 既可以让学生享受线上的 优质课程, 又能保证课程实训环节的先进设备, 但仍 未从根本上解决仪器设备的投入比例。

\section{2. 缺乏必要的职业生涯规划}

随着社会分工和精细生产的出现, 岗位和职位也 与日俱增, 职业培训、辅导、规划应时而生。在大学 毕业生就业市场, 市场导向越来越明显, 政府调控和 学校推荐仍然令毕业生就业大军促不安, 学生与用人 单位双向选择让职业认知和职业教育迫在眉睫。对职 业的认识、态度、观点就是地方院校经管毕业生的职 业观, 如对职业评价、择业方向等的认识, 是他们必 须要掌握的。高校教师在对学生进行职业技能与素养 培训时逐渐认识到学生对就业选择的认识往往过于 狭险, 不能做到将自身实力契合, 所谋求岗位如果没 有对自己的职业生涯进行规划与设计, 学生就不能对 自己的性格、兴趣、技能和价值观准确定位, 就不能 找到适合自己的发展方向。

\section{3. 尚未及时转变就业观念}

俗话说, 变则通、通则顺。地方院校没有做好正 确的引导和帮扶, 学生初入职场, 就选择“钱多、活 少、离家近”的工作, 甚至不切实际、高过预期要求 工资高、待遇好且稳定的工作。他们不了解薪酬、待 遇的增高, 是与个人资历、能力、贡献相关的,

\section{4. 自我定位不清晰}

地方院校大多是应用型人才高校, 其办学特色就 是紧紧围绕地方经济社会发展的需求,所培养的人才 也能为社会所需。地方院校生存与发展首先要解决的 问题, 不但涉及到专业学科发展的前途, 也涉及到人 才培养的定位问题。经管类的学生分布在各行各业, 许多经管类大学生自我定位不清晰, 盲目乐观地认为 “什么工作都能做”、“工作随便找”、“只要想工作随时 可以签约”，这些观念加剧了社会与现实间的冲突， 加上人才需求结构性矛盾日渐突出, 经管大学生就业 竞争力仍然很大。有些企业或单位“门庭若市, 熙熙 攘攘”, 有些则是“门庭冷落、鲜有问津”, 学生在激 烈的竞争中落选而诸多抱怨, 用人单位却在痛呼“人 才难求”。

\section{5. 企业对大学生提出更高的实践能力要求}

由于新冠疫情影响，国际政治大国之间的竞争日 趋激烈, 世界经济持续低迷甚至出现衰退现象, 国内 很多企业受到冲击。为了更好地应对复杂的局势, 在 国内外不安因素在社会经济迅速发展进程中, 地方企 业及事业单位对学生质量需求不断提升, 对地方院校 学生实践能力也提出了更高的要求。地方院校虽然组 织学生参与学科实践竞赛, 但还是以文件下达的形式, 缺乏促使创新实践、课外活动有机结合。另外校政企 合作不够深入，合作模式单一、合作渠道不宽。大部 分还是集中在校内实践场所的理论学习、工作环境模 拟教学、实习单位训练, 学生的学习能力、实践能力、 创新能力未真正得到提高。

\section{6. 缺乏一定的专业素养和科学技能}

地方院校为适应社会和市场的需要, 设置与地方 产业集群相关的专业。但是专业的课程体系偏向“专 才教育”模式, 课程设置缺乏行业特点导致学生知识 面狭窄, 在行业内就业因缺乏行业特色而受限, 在行 业外领域就业竞争力则不够强。大学时期是青年人学 习系统的专业知识、训练扎实的职业能力和建立良好 的人际关系的重要阶段, 也是为个人职业生涯打基础 的阶段, 对大学生的就业与未来职业发展具有十分深 远的影响。

\section{5. 经管专业大学生提高就业竞争力路径研究}

\section{1. 适应社会发展, 提倡互联网思维}

地方院校在区域经济社会发展发挥着重要作用, 其本身存在的办学质量不高、社会资源融入不够、内 部治理机制不健全、人才培养与社会需求脱节等问题, 可以通过开放合作对外合作办学来解决。“互联网+” 思维, 就是互联互惠的思维, 就是产教融合的思维, 也是转型提升的思维。不是简单的相加, 或者是单方 面的你来, 然后我往, 而是包容, 是“你中有我, 我 中有你”的双赢关系。与地方及其企业、行业紧密联 系与合作, 不但地方经济得到发展, 企业解决了员工 培养成本、产品质量、设备技术难题, 学校也拓宽了 办学思路, 各类资源配置得到优化, 解决了学校科研 成果转化为生产力等困局与矛盾。这是一种是开放的 思维, 意味着融合、分享、转型和提升, 有助于人才 培养质量的提升和人才综合竞争力的提升。

\section{2. 利用互联网技术掌握优质教育资源, 弥补 线下教育带来的不足}

互联网时代，对空间和时间的利用率都大大提高。 目前高校在淘汰“水课”，建设“金课”，为的就是培养 学生自主学习的能力, 同时满足不同层次学生的个性 化需求, 让课堂活起来、动起来。传统课堂教学给学 生自由讨论的时间非常有限, 看视频、做试题、分组 
讨论、汇报路演等少之又少。通过线下的课堂传统的 教与学，与线上网络授课、提交作业、分组交流相结 合, 教师会有更多时间引导学生进行广度和深度上的 学习探索、研究。学生利用手机进行课前导学、线上 自主学习, 教师在课堂中对重点难点进行讲解, 同时 可进行线上线下深度讨论, 最终以学生参与度、学习 力作为课程考核等方式, 切实提高了学生的专业学习 兴趣, 锻炼学生独立思考的能力, 增强了学生的综合 素质。

\section{3. 推进大数据建设, 开展个人职业能力测评}

通过职业能力测评, 了解自己的综合职业能力状 况, 了解自己能力的优势和劣势, 让大学生全方位提 高自我认知, 并开展职业生涯规划制定。开展专业能 力测评, 了解自己的专业能力, 制定专业的学习计划。 开展职业风格测评，了解自己的职业倾向，了解企业 用人单位各种岗位的能力要求, 发挥优势, 找到差距, 最终, 快速精准的在线职业能力学习提升, 提高自身 就业竞争力。高校的职业生涯课程在经管新生刚入校 就可以进行, 从最基本的自我认知开始, 进行链条式 的全过程指导, 构建针对性指导生态链, 全过程、全 方位帮助学生认识自我、树立目标、做好定位。

\section{4. 加强信息化建设, 助推大学生就业}

在信息化时代, 人们更加关注社会未来的发展趋 势, 知识创新成为社会发展的主要动力。由于大数据、 云计算兴起的综合影响, 在当今社会, 信息化广泛覆 盖社会的方方面面, 传统手工录入式的信息获取, 也 变成线上线下交替进行。通过大数据分析技术，使得 高校在“智慧校园”建设方面的脚步逐渐加快。由此, 获取信息的方式更加快捷、便捷, 数据价值化的成本 也在降低。通过学生的择业喜好、意向城市、浏览习 惯等数据, 可以较为精准把握毕业生就业的倾向, 对 经管大学生就业择业观念、态度进行有效引导, 为实 施精准就业政策和帮扶措施提供有力的支持。高校要 利用好互联网信息平台, 通过数据抓取、分析, 在毕 业生和用人单位双向数据有效性、真实性的前提下, 对新型用工关系进行专题分析和研究, 有针对性引入 用人单位和岗位, 保障大学生就业权利。

\section{5. 开展“互联网+”创新创业教育, 助力大学 生专业实践能力提升}

“互联网+”已经成为国家战略层面的要求。“互联 网+”背景下大学生创新就业政策的实施, 有助于营造 了良好的创业环境, 有效地缓解大学生的就业压力。 人的一生可以通过多种途径来获得知识和技能, 教育、 培训、交流和工作是最重要的途径。创新创业教育及 活动中的头脑风暴、小组和专家会议、撰写商业计划 书、社会实践调查、查阅参考文献、商业或非商业路 演等, 都是创新创业教育实践下学生提升能力的环节。 地方政府致力于培育和打造新的经济增长点, 加快缩
小与发达地区发展差距。这既是机遇也是挑战，经管 类大学生当积极参加创新创业实践中, 参与企业创办 过程中的技术开发和公司运营，提升就业竞争力。

\section{REFERENCES}

[1] Leilei Yan. About Internet plus to boost college students' employment and entrepreneurship [J]. Modern marketing, 2019(05):254-256.

[2] Chang $\mathrm{Xu}$, Lanlan Liu. Improving the employability of college graduates with difficulties[J]. Science and technology wind, 2019(06):232

[3] Youjun Li, Qiang Shao, Hongying Liu. The performance and Countermeasures of the lack of employability of economics and management students in industry colleges[J]. Education exploration, 2010(04):71-72

[4] Fen Yang. Research on the employment competitiveness of university graduates in the background of Internet plus_-from the perspective of the cultivation of College Students' own abilities[J], Journal of Jiamusi university, 2017 (09): 242-243.

[5] Qian Chen. Research on the cultivation of College Students' employment competency in the background of Internet plus[J]. Knowledge economy, 2020 (07): 164-166. 